\title{
Impact of Novel Resistance Profiles in HIV-1 Reverse Transcriptase on Phenotypic Resistance to NVP
}

\author{
Liyan Jiao, Hanping Li, Lin Li, Daomin Zhuang, Yongjian Liu, Zuoyi Bao, \\ Siyang Liu, and Jingyun Li
}

\begin{abstract}
State Key Laboratory of Pathogen and Biosecurity, Institute of Microbiology and Epidemiology, Academy of Military Medical Science, Beijing 100071, China

Correspondence should be addressed to Jingyun Li, lijy@nic.bmi.ac.cn

Received 28 September 2011; Accepted 17 December 2011

Academic Editor: Ricardo Sobhie Diaz

Copyright ( $\odot 2012$ Liyan Jiao et al. This is an open access article distributed under the Creative Commons Attribution License, which permits unrestricted use, distribution, and reproduction in any medium, provided the original work is properly cited.
\end{abstract}

\begin{abstract}
Objective. To clarify the impact of H221Y mutation on drug resistance to NVP. Methods. 646 bp HIV-1 pol gene fragments (from 592 to 1237 nucleotide) with different NNRTIs mutation profiles from AIDS patients receiving antiretroviral therapy containing NVP regimens were introduced into pNL4-3 backbone plasmid. H221Y and (or) Y181C mutations were reverted to wild type amino acids by site-directed mutagenesis, then strains containing various mutation patterns were packaged. Phenotypic drug resistance was analyzed on TZM-bl cells. Results. 12 strains containing different drug-resistant mutation profiles were constructed, including the K101Q series (K101Q/Y181C/H221Y, K101Q/Y181C, K101Q/H221Y, and K101Q), the V179D series (V179D/Y181C/H221Y, V179D/Y181C, V179D/H221Y, and V179D), and the K103N series (K103N/Y181C/H221Y, K103N/Y181C, K103N/H221Y, K103N). For strains containing the mutation profiles (K101Q/Y181C, K101Q, V179D/Y181C, V179D, K103N/Y181C, and K103N), the presence of H221Y reduced NVP susceptibility by $2.1 \pm 0.5$ to $3.6 \pm 0.5$ fold. To the mutation profiles K101Q/H221Y, K101Q, V179D/H221Y, V179D, K103N/H221Y, and K103N, the presence of Y181C reduced NVP susceptibility by $41.9 \pm 8.4$ to $1297.0 \pm 289.1$ fold. For the strains containing K101Q, V179D, and K103N, the presence of Y181C/H221Y combination decreased NVP susceptibility by $100.6 \pm 32.5$ to $3444.6 \pm 834.5$ fold. Conclusion. On the bases of various NNRTIs mutation profiles, Y181C remarkably improved the $\mathrm{IC}_{50}$ to NVP, although $\mathrm{H} 221$ Ymutation alone just increases $2.1 \sim 3.6$-fold resistance to NVP, the mutation could improve 100.6 3444.6-fold resistance to NVP when it copresent with Y181C, the phenotypic drug resistance fold was improved extremely. For strains containing the mutation profiles (K101Q/Y181C, K101Q, V179D/Y181C, V179D, K103N/Y181C, and K103N), the presence of H221Y reduced NVP susceptibility by $2.1 \pm 0.5$ to $3.6 \pm 0.5$ fold.
\end{abstract}

\section{Introduction}

The nonnucleoside reverse transcriptase inhibitors (NNRTIs) are small molecules which can bind to a nonactive hydrophobic site pocket close to the catalytic domain of RT (termed NNRTI-binding pocket). The binding of NNRTIs to $\mathrm{RT}$ could alter the structure of RT and block the polymerase activity of RT. As the results, the replications of HIV-1 were inhibited. However, despite their high efficiencies and low toxicities, the use of NNRTIs is hampered owing to the rapid selection of drug-resistant HIV-1 strains [1,2]. Therefore, a deeper understanding of resistance is necessary in order to effectively prevent and manage HIV-1 drug resistance.
Almost all NNRTIs-related mutations were identified with their location in binding pocket or near the pocket [3]. These mutations can change the size, shape, and polarity of the pocket and affect the binding of NNRTIs accordingly [4]. There are four types of NNRTIs-resistant mutations: (1) Primary mutation: these mutations emerge earliest during therapy and cause high-level resistance to one or more NNRTIs, including K103N/S, Y181C/I/V, V106A/M, Y188L/C/H, and G190A/S/E. All these mutations can lead to high-level resistance to NVP. (2) Secondary mutation: these mutations usually appear with primary mutations but occasionally occur by themselves. Several of these mutations, particularly K101E/P and M230L, have been associated with significant 
resistance to multiple NNRTIs. (3) Minor nonpolymorphic mutation and accessory mutation: these mutations emerge alone or couple with other NNRTIs-resistant mutations and confer decreasing NNRTIs susceptibility persistently. This type of mutation consists of A98G, K101Q, V108I, and V179D/E. These mutations, such as K101Q and V179I, often occur with other primary mutations. In previous study, in contrast with NRTIs resistance, a single NNRTIs mutation in HIV-1 RT can lead to high-level resistance to multi-NNRTIs (including efavirenz and nevirapine). So in the past, researchers seldom pay attention to the NNRTIsresistant profiles resulting from therapy failure because a single NNRTI treatment failure always means the second NNRTI therapy failure [5-7].

$\mathrm{H} 221 \mathrm{Y}$ was recently found as an NNRTIs mutation which confers resistance to NVP. Our previous study showed that the virus carrying K103N/Y181C/H221Y mutation combination could replicate stably in vitro in absence of drugs [8]. However, the impact of $\mathrm{H} 221 \mathrm{Y}$ on NNRTI susceptibility has been poorly characterized, and the interaction of $\mathrm{H} 221 \mathrm{Y}$ with other mutations is yet indistinct. The objective of this study is to clarify the impact of $\mathrm{H} 221 \mathrm{Y}$ by itself and combination with other mutations on drug resistance to NVP.

\section{Materials and Methods}

Selection of Plasma Samples. Plasma samples were collected from 3 AIDS patients in clinical cohort receiving antiretroviral therapy [nevirapine (NVP) + zidovudine (AZT) + didanosine (ddI)]. All patients have written informed consent. Genotype-resistant results of these patients showed all samples contained three NNRTIs mutations (Y181C/H221Y plus another mutation) which conferred resistance to NVP.

Viral RNA Extraction and One-Step RT PCR. RNA was extracted from $200 \mu \mathrm{L}$ plasma using High Pure Viral RNA Kit (Roche Corp.) following the protocol provided with kits. HIV-1 pol protease and reverse transcriptase genes were obtained by one-step RT PCR.

Cloning of the HIV-1 Protease and RT (Reverse Transcriptase) Gene PCR Products. The PCR products were cleaned by Wizard SV Gel and PCR Clean-Up System (Promega Corp.) and ligated with PMD18-T Vector (TaKaRa Biotechnology Co., Ltd.), then transformed into E. coli $\mathrm{DH} 5 \alpha$.

Selection of Clones with 3 Different Mutation Profiles to NVP. Several clones from each transformation were sequenced, and 3 clones containing 3 different NNRTIs mutation profiles, including K101Q/Y181C/H221Y, V179D/ Y181C/H221Y, and K103N/Y181C/H221Y, were selected.

Construction of 12 Clones with Different NVP-Resistant Mutation Profiles Using Site-Directed Mutagenesis. Three fragments were constructed to convert mutant RT $221(\mathrm{Y})$ to wild-type (H) or (/and) convert mutant RT 181 (C) to wildtype $(\mathrm{Y})$ by site-directed mutant-genesis kit (TaKaRa Mutan
BEST kit, TaKaRa Biotechnology Co. Ltd.) with mutagenic primers: $221 \mathrm{Y} \rightarrow \mathrm{H}, 5^{\prime}$-ACAAAAAACATCAGAAA GAACCTCCAT-3' (H221-F (C-6/P-110)), 5' -ACAAAAAACATCAGAAAGAACCCCC-3' (H221-F(P-22)), 5' -CTGGTGTGGTAAATCCCCACCT-3' (H221-R(C-6-2)), 5' -CTGGTGTGTAAAACCCCCACCTTAAC-3' (H221-R (P-22)), and $5^{\prime}$ CTGGTGT GTAAAATCCCCACCTCAA-3' (H221-R(P$110)) ; 181 \mathrm{C} \rightarrow \mathrm{Y}, 5^{\prime}$-ATAGTTATC TATC AATACATGGATGATTTGTATGT-3' (Y181-F(C-6/P-110)829), 5' -ATGGAAATCT ATCAATACATGGATGATTTGT-3' (Y181-F(P-22-6) 829), 5'-GTCTGGATTTTGTT TTCTAAAAGGCTC-3' (Y181-R 828). Different mutation profiles were created including K101Q/Y181C/ H221Y, K101Q/Y181C, K101Q/ H221Y, K101Q, V179D/Y181C/ H221Y, V179D/Y181C, V179D/H221Y, V179D, K103N/ Y181C/H221Y, K103N/ Y181C, K103N/H221Y, and K103N. All of mutations were confirmed by sequencing with primers: $5^{\prime}$-GCCATAAAGAAAAAARACAGTACTARA-3' (Mut-F 481) and 5'TCATTCTTGCATAYTTTCCTGT TTT-3' (Mut-R 1369).

Insertion of the RT Fragments into the Backbone pNL4-3 Vector. Two restriction sites (Sbf/ and Age/) were created in the 12 fragments with different mutation profiles. The $646 \mathrm{bp}$ fragments were digested with Sbf/ and Age/, purified with Wizard SV Gel and PCR Clean-Up System (Promega Corp.), and inserted into backbone pNL4-3 vector which had been removed the corresponding fragments.

Preparation of Plasmid DNA. The mutations introduced into pNL4-3 vectors were confirmed by sequencing primers: $5^{\prime}$-GCCATAAAGAAAAAAGACAGTACTAAA-3' (NL + aimF481) and $5^{\prime}$-CCTTCATTCTTGCATATTTTCCT-3' (NL + aim-R 1372) before being prepared by QIAGEN Plasmid Midi Kit (25) (QIAGEN Corp.).

Cells and Media. The 293T and the TZM-bl cell lines were presented by the nucleic acid vaccine laboratory of University of Massachusetts Medical School and were maintained in DMEM (Invitrogen, Corp.) medium containing 10\% fetal bovine serum.

Transfections, Infections, and NVP Susceptibility Assays. The ligated pNL4-3 plasmids were transfected into 293T cells by using Lipofectamine 2000 (Invitrogen, Corp.). TCID 50 of the virus culture supernatant and $\mathrm{IC}_{50} \mathrm{~s}$ to NVP were detected by using TZM-bl cells. The $\mathrm{IC}_{50} \mathrm{~s}$ were determined by concentration-response curves of the $\log _{10}$ NVP concentration versus percent inhibition of virus.

\section{Results}

Construction 12 HIV-1 Virus Containing Different Mutation Profiles. These viruses were named 101Q-1, 101Q-2, 101Q3, 101Q-4, 179D-1, 179D-2, 179D-3, 179D-4, 103N-1, $103 \mathrm{~N}-2,103 \mathrm{~N}-3$, and $103 \mathrm{~N}-4$; the mutation patterns they contained were K101Q/Y181C/H221Y, K101Q/Y181C, K101Q/H221Y, K101Q, V179D/Y181C/ H221Y, V179D/ Y181C, V179D/H221Y, V179D, K103N/ Y181C/H221Y, 
TABLE 1: The greatest initial NVP concentrations of every virus, $\mathrm{IC}_{50}(\mu \mathrm{M})$ of every virus and the increased NVP resistance compared to pNL4-3.

\begin{tabular}{lcccc}
\hline Virus no. & Mutation patterns & $\begin{array}{c}\text { Greatest concentration } \\
\text { of NVP }(\mu \mathrm{M})\end{array}$ & $\mathrm{IC}_{50}(\mu \mathrm{M})$ & $\begin{array}{c}\text { Median fold of IC50 increased } \\
\text { compared to pNL4-3 }( \pm \text { S.D. })\end{array}$ \\
\hline $101 \mathrm{Q}-1$ & $\mathrm{~K} 101 \mathrm{Q} / \mathrm{Y} 181 \mathrm{C} / \mathrm{H} 221 \mathrm{Y}$ & 1000 & $108.2 \pm 1.9$ & $3740.8( \pm 314.1)$ \\
$101 \mathrm{Q}-2$ & $\mathrm{~K} 101 \mathrm{Q} / \mathrm{Y} 181 \mathrm{C}$ & 200 & $47.8 \pm 18.1$ & $1490.9( \pm 354.4)$ \\
$101 \mathrm{Q}-3$ & $\mathrm{~K} 101 \mathrm{Q} / \mathrm{H} 221 \mathrm{Y}$ & 2 & $0.14 \pm 0.05$ & $4.4( \pm 1.2)$ \\
$101 \mathrm{Q}-4$ & $\mathrm{~K} 101 \mathrm{Q}$ & 0.5 & $0.04 \pm 0.01$ & $1.2( \pm 0.2)$ \\
$179 \mathrm{D}-1$ & $\mathrm{~V} 179 \mathrm{D} / \mathrm{Y} 181 \mathrm{C} / \mathrm{H} 221 \mathrm{Y}$ & 500 & $162.6 \pm 47.5$ & $5090.6( \pm 744.6)$ \\
$179 \mathrm{D}-2$ & $\mathrm{~V} 179 \mathrm{D} / \mathrm{Y} 181 \mathrm{C}$ & 500 & $45.0 \pm 12.8$ & $1413.0( \pm 269.8)$ \\
$179 \mathrm{D}-3$ & $\mathrm{~V} 179 \mathrm{D} / \mathrm{H} 221 \mathrm{Y}$ & 5 & $0.4 \pm 0.0$ & $13.4( \pm 1.9)$ \\
$179 \mathrm{D}-4$ & $\mathrm{~V} 179 \mathrm{D}$ & 1.25 & $0.1 \pm 0.0$ & $4.6( \pm 1.3)$ \\
$103 \mathrm{~N}-1$ & $\mathrm{~K} 103 \mathrm{~N} / \mathrm{Y} 181 \mathrm{C} / \mathrm{H} 221 \mathrm{Y}$ & 1000 & $191.1 \pm 91.4$ & $5859.3( \pm 1648.2)$ \\
$103 \mathrm{~N}-2$ & $\mathrm{~K} 103 \mathrm{~N} / \mathrm{Y} 181 \mathrm{C}$ & 1000 & $89.2 \pm 22.7$ & $2802.4( \pm 124.1)$ \\
$103 \mathrm{~N}-3$ & $\mathrm{~K} 103 \mathrm{~N} / \mathrm{H} 221 \mathrm{Y}$ & 50 & $4.4 \pm 0.9$ & $139.2( \pm 8.2)$ \\
$103 \mathrm{~N}-4$ & $\mathrm{~K} 103 \mathrm{~N}$ & 25 & $2.0 \pm 0.4$ & $63.8( \pm 3.1)$ \\
$\mathrm{Con}-1$ & & 1 & $0.03 \pm 0.01$ & \\
\hline
\end{tabular}

K103N/Y181C, K103N/H221Y, and K103N. As the control virus, Con-1 was pNL4-3 without any drug-resistant mutations. The virus name and corresponding drug resistance mutation profiles were indicated at Table 1 .

$I C_{50} s$ of 13 Virus. Firstly, we measured the TCID $_{50}$ s of recombinant virus with TZM-bl cells. TCID ${ }_{50}$ s of virus 101Q-1, 101Q-2, 101Q-3, 101Q-4, 179D-1, 179D-2, 179D3, 179D-4, 103N-1, 103N-2, 103N-3, 103N-4, and Con-1 were 10687, 6250, 18275, 6250, 156250, 21555, 45305, 31250, $31250,18275,13975$, and 4780 per milliliter, respectively. To determine the $\mathrm{IC}_{50} \mathrm{~s}$ of NVP versus every virus, we identified the concentration range of high and low inhibition and ensured that the greatest concentration can inhibit 95\% viruses at least, and the lowest concentration can inhibit $10 \sim 15 \%$. NVP concentrations of all viruses were diluted double successively except virus Con-1 triplicate successively. The greatest concentrations of every virus were showed in Table 1 .

Three independent experiments were performed in triplicate. The curves of percent inhibition of virus to $\log _{10} \mathrm{NVP}$ concentration were created and showed in Figures 1, 2 and 3. $\mathrm{IC}_{50} \mathrm{~s}$ of 13 viruses were separately $108.2 \pm 1.9 \mu \mathrm{M}, 47.8 \pm$ $18.1 \mu \mathrm{M}, 0.14 \pm 0.05 \mu \mathrm{M}, 0.04 \pm 0.01 \mu \mathrm{M}, 162.6 \pm 47.5 \mu \mathrm{M}$, $45.0 \pm 12.8 \mu \mathrm{M}, 0.4 \pm 0.0 \mu \mathrm{M}, 0.1 \pm 0.0 \mu \mathrm{M}, 191.1 \pm 91.4 \mu \mathrm{M}$, $89.2 \pm 22.7 \mu \mathrm{M}, 4.4 \pm 0.9 \mu \mathrm{M}, 2.0 \pm 0.4 \mu \mathrm{M}$, and $0.03 \pm 0.01 \mu \mathrm{M}$ (Table 1).

Susceptibility Reduction of Various Mutation Patterns Compared to pNL4-3. Compared to pNL4-3, the resistance values (folds of $\mathrm{IC}_{50}$ increased) derived from viruses carrying different mutation profiles such as K101Q/ Y181C/ H221Y, K101Q/Y181C, K101Q/H221Y, K101Q, V179D/ Y181C/H221Y, V179D/Y181C, V179D/H221Y, V179D, K103N/Y181C/H221Y, K103N/Y181C, K103N/ H221Y, and
TABle 2: Contribution of H221Y, Y181C, H221Y/Y181C to an increased NVP resistance based on various mutation profiles.

\begin{tabular}{lcc}
\hline Aimed mutation & $\begin{array}{c}\text { Base mutation } \\
\text { profile }\end{array}$ & $\begin{array}{c}\text { Increased fold of } \mathrm{IC}_{50} \\
( \pm \text { S.D. })\end{array}$ \\
\hline $\mathrm{H} 221 \mathrm{Y}$ & $\mathrm{K} 101 \mathrm{Q} / \mathrm{Y} 181 \mathrm{C}$ & $2.2( \pm 0.9)$ \\
$\mathrm{H} 221 \mathrm{Y}$ & $\mathrm{K} 101 \mathrm{Q}$ & $3.2( \pm 0.3)$ \\
$\mathrm{H} 221 \mathrm{Y}$ & $\mathrm{V} 179 \mathrm{D} / \mathrm{Y} 181 \mathrm{C}$ & $3.6( \pm 0.5)$ \\
$\mathrm{H} 221 \mathrm{Y}$ & $\mathrm{V} 179 \mathrm{D}$ & $3.0( \pm 0.4)$ \\
$\mathrm{H} 221 \mathrm{Y}$ & $\mathrm{K} 103 \mathrm{~N} / \mathrm{Y} 181 \mathrm{C}$ & $2.1( \pm 0.5)$ \\
$\mathrm{H} 221 \mathrm{Y}$ & $\mathrm{K} 103 \mathrm{~N}$ & $2.2( \pm 0.1)$ \\
$\mathrm{Y} 181 \mathrm{C}$ & $\mathrm{K} 101 \mathrm{Q} / \mathrm{H} 221 \mathrm{Y}$ & $759.1( \pm 41.9)$ \\
$\mathrm{Y} 181 \mathrm{C}$ & $\mathrm{K} 101 \mathrm{Q}$ & $1297.0( \pm 289.1)$ \\
$\mathrm{Y} 181 \mathrm{C}$ & $\mathrm{V} 179 \mathrm{D} / \mathrm{H} 221 \mathrm{Y}$ & $390.0( \pm 101.6)$ \\
$\mathrm{Y} 181 \mathrm{C}$ & $\mathrm{V} 179 \mathrm{D}$ & $312.5( \pm 45.3)$ \\
$\mathrm{Y} 181 \mathrm{C}$ & $\mathrm{K} 103 \mathrm{~N} / \mathrm{H} 221 \mathrm{Y}$ & $41.9( \pm 8.4)$ \\
$\mathrm{Y} 181 \mathrm{C}$ & $\mathrm{K} 103 \mathrm{~N}$ & $47.9( \pm 4.2)$ \\
$\mathrm{Y} 181 \mathrm{C} / \mathrm{H} 221 \mathrm{Y}$ & $\mathrm{K} 101 \mathrm{Q}$ & $3444.6( \pm 834.5)$ \\
$\mathrm{Y} 181 \mathrm{C} / \mathrm{H} 221 \mathrm{Y}$ & $\mathrm{V} 179 \mathrm{D}$ & $1132.6( \pm 180.4)$ \\
$\mathrm{Y} 181 \mathrm{C} / \mathrm{H} 221 \mathrm{Y}$ & $\mathrm{K} 103 \mathrm{~N}$ & $100.6( \pm 32.5)$ \\
\hline
\end{tabular}

$\mathrm{K} 103 \mathrm{~N}$ were $3740.8 \pm 314.1,1490.9 \pm 354.4,4.4 \pm 1.2$, $1.2 \pm 0.2,5090.6 \pm 744.6,1413.0 \pm 269.8,13.4 \pm 1.9,4.6 \pm 1.3$, $5859.3 \pm 1648.2,2802.4 \pm 124.1,139.2 \pm 8.2$, and $63.8 \pm 3.1$ folds, respectively (Table 1).

Association of H221Y with an Increased NVP IC I $_{50}$ Based on Various Mutation Profiles. As for different mutation patterns including K101Q/Y181C, K101Q, V179D/Y181C, V179D, K103N/Y181C and K103N, H221Y conferred NVP IC 50 increased folds $2.2 \pm 0.9,3.2 \pm 0.3,3.6 \pm 0.5,3.0 \pm 0.4,2.1 \pm 0.5$, and $2.2 \pm 0.1$, respectively (Table 2 ). 

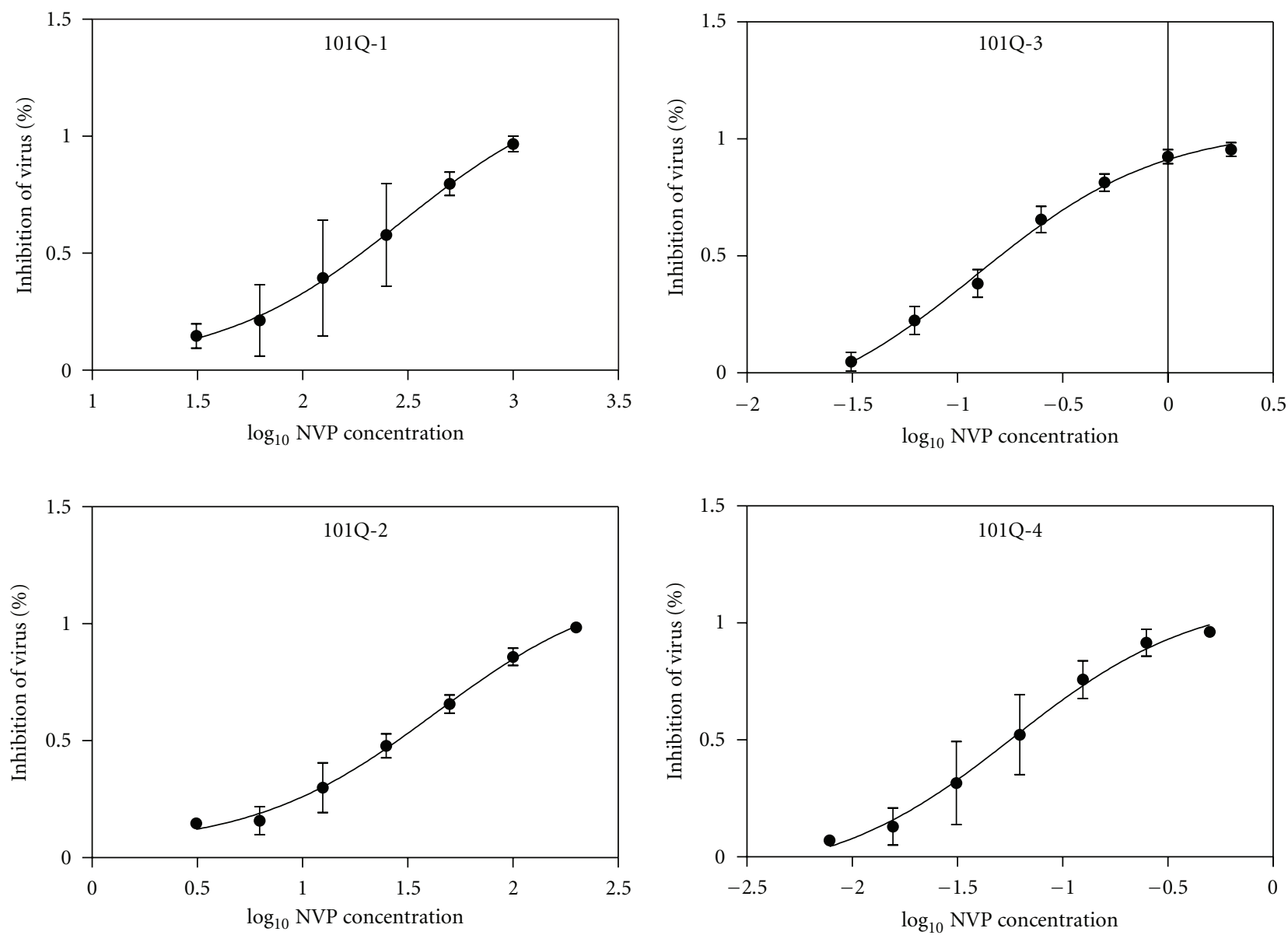

FIgURE 1: The curves of percent inhibition of virus 101Q-1 101Q-4 to $\log _{10}$ NVP concentration.

TABle 3: The complete set of differences from consensus B (from 99 to $313 \mathrm{AA}$ in pol region).

\begin{tabular}{|c|c|c|c|c|c|c|c|c|c|c|c|c|c|c|c|c|c|c|c|c|c|}
\hline \multirow{2}{*}{ Virus } & \multicolumn{21}{|c|}{ Position of AA in pol region } \\
\hline & 101 & 103 & 135 & 162 & 178 & 179 & 181 & 200 & 203 & 207 & 215 & 221 & 228 & 272 & 277 & 278 & 292 & 293 & 297 & 311 & 312 \\
\hline Consensus B & $\mathbf{K}$ & $\mathrm{K}$ & I & $S$ & I & $\mathrm{V}$ & $\mathrm{Y}$ & $\mathrm{T}$ & $\mathrm{E}$ & Q & $\mathrm{T}$ & $\mathbf{H}$ & $\mathrm{L}$ & A & $\mathrm{K}$ & Q & $\mathrm{V}$ & I & $\mathrm{E}$ & $\mathrm{K}$ & $\mathrm{E}$ \\
\hline 101Q-1 & Q & - & $\mathrm{R}$ & $\mathrm{C}$ & - & - & $\mathrm{C}$ & A & - & - & - & $\mathbf{Y}$ & - & - & $\mathrm{R}$ & $\mathrm{E}$ & - & - & - & - & - \\
\hline 101Q-2 & $\mathbf{Q}$ & - & $\mathrm{R}$ & $\mathrm{C}$ & - & - & $\mathrm{C}$ & A & - & - & - & - & - & - & $\mathrm{R}$ & $\mathrm{E}$ & - & - & - & - & - \\
\hline 101Q-3 & $\mathbf{Q}$ & - & $\mathrm{R}$ & $\mathrm{C}$ & - & - & - & A & - & - & - & $\mathrm{Y}$ & - & - & $\mathrm{R}$ & $\mathrm{E}$ & - & - & - & - & - \\
\hline 101Q-4 & $\mathrm{Q}$ & - & $\mathrm{R}$ & $\mathrm{C}$ & - & - & - & A & - & - & - & - & - & - & $\mathrm{R}$ & $\mathrm{E}$ & - & - & - & - & - \\
\hline 179D-1 & - & - & $\mathrm{V}$ & $\mathrm{C}$ & $\mathrm{M}$ & $\mathrm{D}$ & $\mathrm{C}$ & A & G & $\mathrm{E}$ & $\mathbf{Y}$ & $\mathrm{Y}$ & $\mathrm{R}$ & - & $\mathrm{R}$ & $\mathrm{E}$ & I & $\mathrm{V}$ & - & - & - \\
\hline 179D-2 & - & 一 & $\mathrm{V}$ & $\mathrm{C}$ & $\mathrm{M}$ & $\mathrm{D}$ & $\mathrm{C}$ & A & G & $\mathrm{E}$ & $\mathbf{Y}$ & - & $\mathrm{R}$ & - & $\mathrm{R}$ & $\mathrm{E}$ & I & $\mathrm{V}$ & - & - & - \\
\hline 179D-3 & - & - & $\mathrm{V}$ & $\mathrm{C}$ & $\mathrm{M}$ & $\mathrm{D}$ & - & A & G & $\mathrm{E}$ & Y & $\mathrm{Y}$ & $\mathrm{R}$ & - & $\mathrm{R}$ & $\mathrm{E}$ & I & $\mathrm{V}$ & - & - & - \\
\hline 179D-4 & - & - & $\mathrm{V}$ & $\mathrm{C}$ & $\mathrm{M}$ & $\mathrm{D}$ & - & A & G & $\mathrm{E}$ & $\mathbf{Y}$ & - & $\mathrm{R}$ & - & $\mathrm{R}$ & $\mathrm{E}$ & I & $\mathrm{V}$ & - & - & - \\
\hline $103 \mathrm{~N}-1$ & - & $\mathrm{N}$ & $\mathrm{V}$ & $\mathrm{C}$ & - & - & $\mathrm{C}$ & A & - & - & Y & $\mathbf{Y}$ & - & S & $\mathrm{R}$ & $\mathrm{E}$ & - & - & K & $S$ & K \\
\hline $103 \mathrm{~N}-2$ & - & $\mathrm{N}$ & $\mathrm{V}$ & $\mathrm{C}$ & - & - & $\mathrm{C}$ & A & - & - & $\mathbf{Y}$ & - & - & S & $\mathrm{R}$ & $\mathrm{E}$ & - & - & K & S & $\mathrm{K}$ \\
\hline $103 \mathrm{~N}-3$ & - & $\mathrm{N}$ & $\mathrm{V}$ & $\mathrm{C}$ & - & - & - & A & - & - & $\mathbf{Y}$ & $\mathbf{Y}$ & - & $S$ & $\mathrm{R}$ & $\mathrm{E}$ & - & - & K & $S$ & K \\
\hline $103 \mathrm{~N}-4$ & - & $\mathrm{N}$ & $\mathrm{V}$ & $\mathrm{C}$ & - & - & - & A & - & - & Y & - & - & S & $\mathrm{R}$ & $\mathrm{E}$ & - & - & K & S & $\mathrm{K}$ \\
\hline
\end{tabular}

Association of Y181C with an Increased NVP IC $\mathrm{C}_{50}$ Based on Various Mutation Profiles. In relation to various mutation profiles such as K101Q/H221Y, K101Q, V179D/H221Y, V179D, K103N/H221Y, and K103N, Y181C mutation increased folds of $\mathrm{NVP}$ and $\mathrm{IC}_{50}$ s were 759.1 $\pm 41.9,1297.0 \pm$
289.1, $390.0 \pm 101.6,312.5 \pm 45.3,41.9 \pm 8.4$, and 47.9 \pm 4.2 , respectively (Table 2 ).

Association of $Y 181 \mathrm{C} / \mathrm{H} 221 \mathrm{Y}$ with an Increased NVP IC $\mathrm{C}_{50}$ Based on Various Mutation Profiles. Concerning K101Q, 

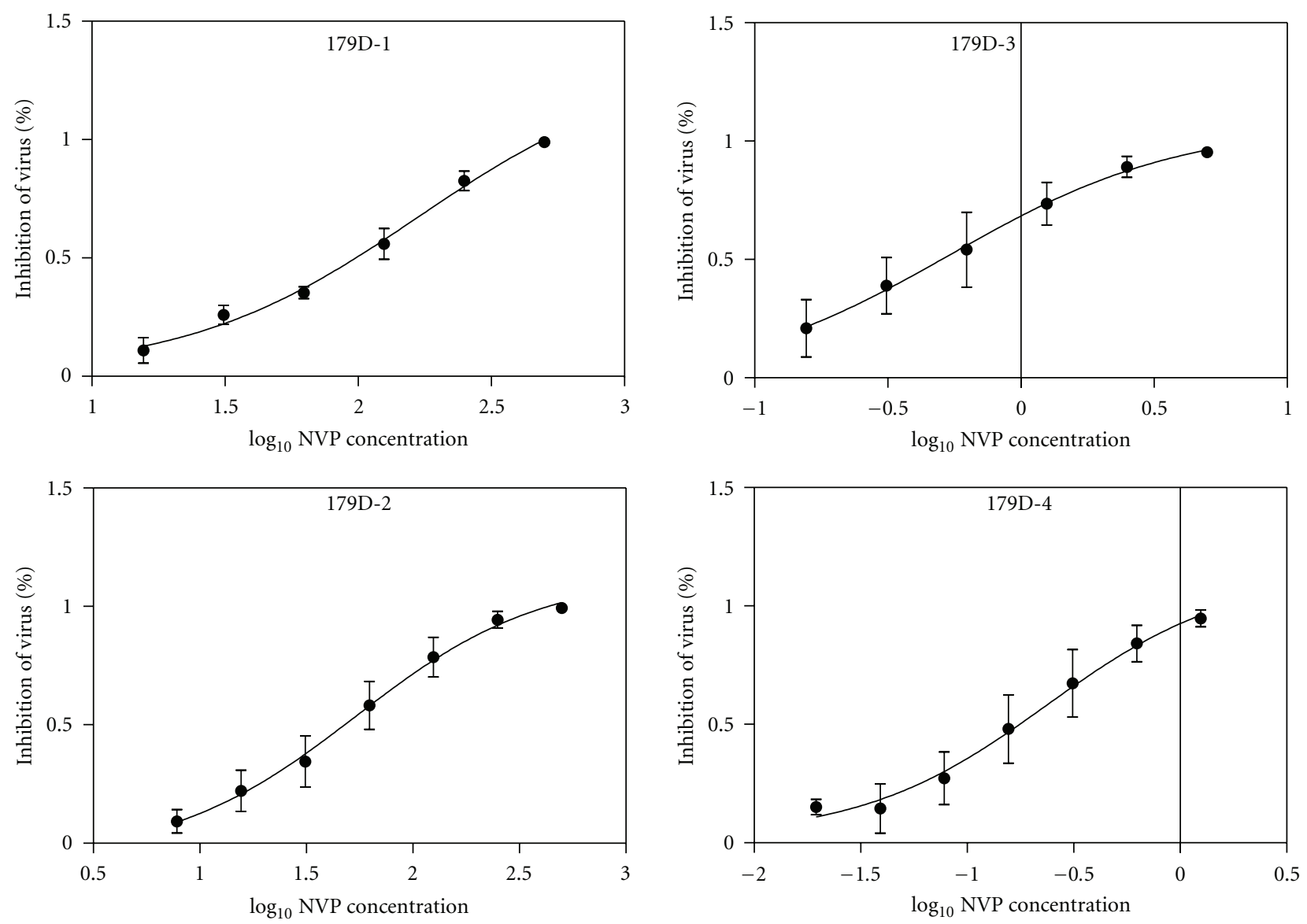

Figure 2: The curves of percent inhibition of virus 179D-1 179D-4 to $\log _{10}$ NVP concentration.

V179D, and K103N, Y181C/H221Y mutation combination improved the $\mathrm{IC}_{50} \mathrm{~s}$ of NVP $3444.6 \pm 834.5,1132.6 \pm 180.4$, and $100.6 \pm 32.5$ folds, respectively (Table 2).

The Complete Set of Differences from Consensus B. The differences from consensus B were listed in Table 3 , and these additional mutations might affect susceptibility.

\section{Discussion}

H221Y was first reported related to NRTI treatment in 2003 [9], but in recent study, H221Y was concerned associated with exposed to NNRTIs $[6,10]$. Ceccherini-Silberstein et al. found the prevalence rate of $\mathrm{H} 221 \mathrm{Y}$ in isolates from patients failing NVP treatment was $10.3 \%$ and the mutation was included in the top 10 and 15 determinants for NVP and EFV resistance, respectively, ranking even above some classical NNRTI resistance mutations, such as K101E, V108I, and G190E [6]. The group found H221Y was strongly associated with the use of NVP and showed positive interactions with Y181C and was also negatively associated with the use of ZDV and with TAMs (particularly TAMs-2, such as D67N, K70R, K219Q/E, and T215F) and was then associated with an increased susceptibility to ZDV. When H221Y was copresent with TAMs-2, the ZDV susceptibility was even greater than that observed when TAMs-2 were copresent with Y181C. The presence of H221Y along with Y181C was associated with a 12.4-fold increase in NVP resistance. Jiang et al. found that the occurrence of the H221Y was $19.8 \%$ in 91 patients receiving nevirapine and lamivudine plus stavudine $(57.1 \%)$ or zidovudine $(42.9 \%)$ [10]. Reuman et al. analyzed viruses from 13039 individuals with sequences containing at least one of 52 published NNRTI-selected mutations; the frequency of $\mathrm{H} 221 \mathrm{Y}$ among 1510 viruses from individuals who received nevirapine but no other NNRTI was $12 \%$. H221Y occurred along with Y181C in our study (data not shown) and the virus with mutation pattern $\mathrm{K} 103 \mathrm{~N} / \mathrm{Y} 181 \mathrm{C} / \mathrm{H} 221 \mathrm{Y}$ can replicate stably in vitro without drug pressure [8]. Our study showed that as for the mutation profiles K101Q/Y181C, K101Q, V179D/Y181C, V179D, K103N/Y181C, and K103N, the presence of H221Y, respectively lead to $2.2 \pm 0.9,3.2 \pm 0.3,3.6 \pm 0.5,3.0 \pm 0.4$, $2.1 \pm 0.5$, and $2.2 \pm 0.1$-fold increase in NVP resistance.

Y181C is a very important NNRTIs-related drug resistant mutation, and the mutation can cause high-level resistance to NVP and DLV and low-level resistance to EFV; otherwise, this mutation can increase susceptibility to AZT and TDF. 

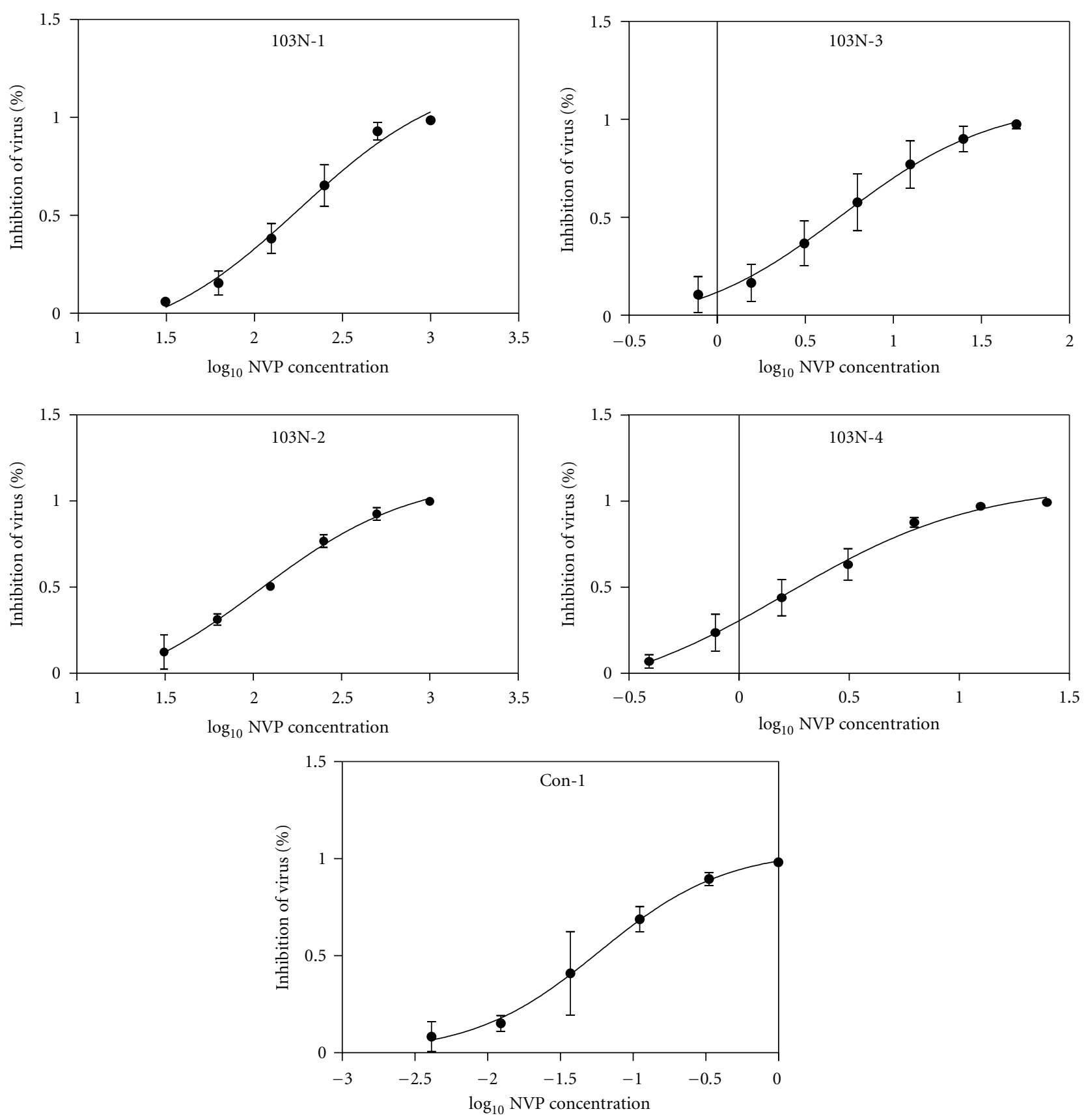

FIgURE 3: The curves of percent inhibition of virus $103 \mathrm{~N}-1 \sim 103 \mathrm{~N}-4$, Con-1 to $\log _{10}$ NVP concentration.

Sungkanuparph group reported the prevalence rate of Y181C was $59.5 \%$ among the 158 NNRTI failure patients (for a median NNRTI treatment period of 88 weeks) [11]. Taiwo et al. found the frequency of Y181C was $42.9 \%$ in the patients receiving NNRTI treatment for a median period of 53 weeks [12]. Y181C presents in $40 \%$ of patients failing NVP and has the third-greatest weight in the SVR (support vector regression) model for NVP resistance [6]. In Reuman group's study [13], Y181C is the most common resistant mutation among the sequences from patients receiving NVP (48\%), and nearly $17 \%(n=2233)$ sequences contained three or more NNRTIs-resistant mutations and these NNRTIsresistant profiles often carried $\mathrm{Y} 181 \mathrm{C}$ and occurred with one or more thymidine analogue mutations, which suggested these mutation pattern might significantly associated with the function of HIV-1 RT. Many studies have reported the phenotype resistance of Y181C, Bacheler et al. [14] found the virus with $\mathrm{K} 103 \mathrm{~N} / \mathrm{Y} 181 \mathrm{C}$ and other mutations conferring above 1600-fold resistance to NVP, and Qari et al. [15] covered the virus containing K101E/Y181C/G190A 
and other mutations could increase 893 -fold resistance to NVP. As we have known [16], Y181C copresent with TAMs2 could increase the susceptibility to ZDV. In our study, mutation patterns K101Q/H221Y, K101Q, V179D/H221Y, V179D, K103N/H221Y, and K103N, Y181C could, respectively, improve $759.1 \pm 41.9,1297.0 \pm 289.1,390.0 \pm 101.6$, $312.5 \pm 45.3,41.9 \pm 8.4$, and $47.9 \pm 4.2$-fold to NVP resistance.

Although H221Y mutation alone just increases $2.1 \sim 3.6$ fold resistance to NVP, the mutation could improve 100.6 3444.6-fold resistance to NVP when it copresent with Y181C. To be specific, to K101Q, V179D, and K103N, Y181C/H221Y could confer $3444.6 \pm 834.5,1132.6 \pm 180.4$, and $100.6 \pm 32.5$ fold resistance to NVP.

Ceccherini-Silberstein et al. [6] described the resistant characters of 9 novel NNRTI-related mutations including K101Q, I135M/T, H221Y, K223E/Q, L228H/R, and V179I. In these novel mutations, K101Q and I135T copresented with K103N which related to the increase resistance of EFV and NVP. Residue 101 may establish hydrogen bonds with EFV and may directly interact with correlated residue 102 by van der Waals interaction. In previous study, the appearance of K101Q might be based on the occurrence of K103N [17]. In other study [18], residue 101 showed negative association with HLA-A2 genotype which suggested, in the presence of HLA-A2 restricted immune response, position 101 may be under negative selective pressure that favors the preservation of the wild-type amino acid. As for residue 179, only V179F mutation did not decrease the susceptibility to etravirine; however, when the mutation combined with Y181C, the viral etravirine susceptibility could be reduced more than 100 fold [19-22]. Thus receiving NNRTIs treatment on long term might result in the accumulation of accessory mutations and lead to higher level of drug resistance.

With the upcoming approval of the new NNRTIs, understanding the efficacy of these NNRTIs mutation profiles shows more and more importance. Further in vitro and clinical studies are therefore necessary to confirm the efficacy of these new mutation patterns. These studies will provide information for deeper understanding of the mechanisms of drug resistance.

\section{Conclusions}

The success of HAART (Highly Active Antiretroviral Therapy) in treating AIDS patients is hampered by the emergence of drug-resistant strains, and more and more studies indicate that there are more drug-resistant mutations than we have known. The roles of these novel mutations in drug resistance have still been indistinct. In this study, we found that Y181C remarkably improved the $\mathrm{IC}_{50}$ to NVP, although the novel mutation $\mathrm{H} 221 \mathrm{Y}$ only slightly conferred resistance to NVP, when it combined with Y181C, the phenotypic drug resistance folds were improved extremely.

\section{Acknowledgments}

This work was supported by the State Key Program of National Natural Science of China (Grant no. 30830088) and the National Natural Science Foundation of China (Grant no. 30800938).

\section{References}

[1] F. Clavel and A. J. Hance, "HIV drug resistance," The New England Journal of Medicine, vol. 350, no. 10, pp. 1023-1035, 2004.

[2] V. A. Johnson, F. Brun-Vezinet, B. Clotet et al., "Update of the drug resistance mutations in HIV-1: fall 2006," Topics in HIV Medicine, vol. 14, no. 3, pp. 125-130, 2006.

[3] S. G. Sarafianos, B. Marchand, K. Das et al., "Structure and function of HIV-1 reverse transcriptase: molecular mechanisms of polymerization and inhibition," Journal of Molecular Biology, vol. 385, no. 3, pp. 693-713, 2009.

[4] M. Geitmann, T. Unge, and U. H. Danielson, "Interaction kinetic characterization of HIV-1 reverse transcriptase nonnucleoside inhibitor resistance," Journal of Medicinal Chemistry, vol. 49, no. 8, pp. 2375-2387, 2006.

[5] W. P. Bannister, L. Ruiz, A. Cozzi-Lepri et al., "Comparison of genotypic resistance profiles and virological response between patients starting nevirapine and efavirenz in EuroSIDA," AIDS, vol. 22, no. 3, pp. 367-376, 2008.

[6] F. Ceccherini-Silberstein, V. Svicher, T. Sing et al., "Characterization and structural analysis of novel mutations in human immunodeficiency virus type 1 reverse transcriptase involved in the regulation of resistance to nonnucleoside inhibitors," Journal of Virology, vol. 81, no. 20, pp. 11507-11519, 2007.

[7] K. Deforche, R. J. Camacho, Z. Grossman et al., "Bayesian network analyses of resistance pathways against efavirenz and nevirapine," AIDS, vol. 22, no. 16, pp. 2107-2115, 2008.

[8] L. Y. Jiao, Z. Y. Bao, H. P. Li et al., "Evolvement of HIV-1 drug resistant mutations in vitro without drug pressure," Chinese Journal of Microbiology and Immunology, vol. 30, no. 5, pp. 431-437, 2010.

[9] M. J. Gonzales, T. D. Wu, J. Taylor et al., "Extended spectrum of HIV-1 reverse transcriptase mutations in patients receiving multiple nucleoside analog inhibitors," AIDS, vol. 17, no. 6, pp. 791-799, 2003.

[10] S. Jiang, H. Xing, X. Si, Y. Wang, and Y. Shao, "Polymorphism of the protease and reverse transcriptase and drug resistance mutation patterns of HIV-1 subtype B prevailing in China," Journal of Acquired Immune Deficiency Syndromes, vol. 42, no. 4, pp. 512-514, 2006.

[11] S. Sungkanuparph, W. Manosuthi, S. Kiertiburanakul, B. Piyavong, and W. Chantratita, "Evaluating the role of Etravirine in the second-line antiretrovinal therapy after failing an initial non-nucleoside reverse transcriptase inhibitorbased regimen in a resource-limited setting," Current HIV Research, vol. 6, no. 5, pp. 474-476, 2008.

[12] B. Taiwo, B. Chaplin, S. Penugonda et al., "Suboptimal etravirine activity is common during failure of nevirapinebased combination antiretroviral therapy in a cohort infected with non-B subtype HIV-1," Current HIV Research, vol. 8, no. 3, pp. 194-198, 2010.

[13] E. C. Reuman, S. Y. Rhee, S. P. Holmes, and R. W. Shafer, "Constrained patterns of covariation and clustering of HIV-1 non-nucleoside reverse transcriptase inhibitor resistance mutations," Journal of Antimicrobial Chemotherapy, vol. 65, no. 7, Article ID dkq140, pp. 1477-1485, 2010.

[14] L. Bacheler, S. Jeffrey, G. Hanna et al., "Genotypic correlates of phenotypic resistance to efavirenz in virus isolates from 
patients failing nonnucleoside reverse transcriptase inhibitor therapy," Journal of Virology, vol. 75, no. 11, pp. 4999-5008, 2001.

[15] S. H. Qari, R. Respess, H. Weinstock et al., "Comparative analysis of two commercial phenotypic assays for drug susceptibility testing of human immunodeficiency virus type 1," Journal of Clinical Microbiology, vol. 40, no. 1, pp. 31-35, 2002.

[16] B. Selmi, J. Deval, K. Alvarez et al., "The Y181C substitution in $3^{\prime}$-azido- $3^{\prime}$-deoxythymidine-resistant human immunodeficiency virus, type 1 , reverse transcriptase suppresses the ATP-mediated repair of the $3^{\prime}$-azido- $3^{\prime}$-deoxythymidine $5^{\prime}$-monophosphate-terminated primer," Journal of Biological Chemistry, vol. 278, no. 42, pp. 40464-40472, 2003.

[17] L. T. Bacheler, E. D. Anton, P. Kudish et al., "Human immunodeficiency virus type 1 mutations selected in patients failing efavirenz combination therapy," Antimicrobial Agents and Chemotherapy, vol. 44, no. 9, pp. 2475-2484, 2000.

[18] C. B. Moore, M. John, I. R. James, F. T. Christiansen, C. S. Witt, and S. A. Mallal, "Evidence of HIV-1 adaptation to HLArestricted immune responses at a population level," Science, vol. 296, no. 5572, pp. 1439-1443, 2002.

[19] H. Azijn, I. Tirry, J. Vingerhoets et al., "TMC278, a nextgeneration nonnucleoside reverse transcriptase inhibitor (NNRTI), active against wild-type and NNRTI-resistant HIV1," Antimicrobial Agents and Chemotherapy, vol. 54, no. 2, pp. 718-727, 2010.

[20] J. Vingerhoets, L. Tambuyzer, H. Azijn et al., "Resistance profile of etravirine: combined analysis of baseline genotypic and phenotypic data from the randomized, controlled Phase III clinical studies," AIDS, vol. 24, no. 4, pp. 503-514, 2010.

[21] J. Vingerhoets, H. Azijn, E. Fransen et al., "TMC125 displays a high genetic barrier to the development of resistance: evidence from in vitro selection experiments," Journal of Virology, vol. 79, no. 20, pp. 12773-12782, 2005.

[22] K. Das, A. D. Clark Jr., P. J. Lewi et al., "Roles of conformational and positional adaptability in structure-based design of TMC125-R165335 (Etravirine) and related non-nucleoside reverse transcriptase inhibitors that are highly potent and effective against wild-type and drug-resistant HIV-1 variants," Journal of Medicinal Chemistry, vol. 47, no. 10, pp. 2550-2560, 2004. 


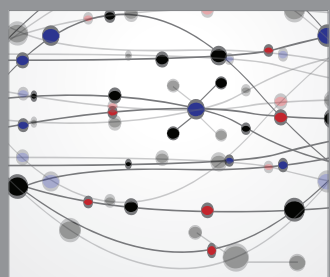

The Scientific World Journal
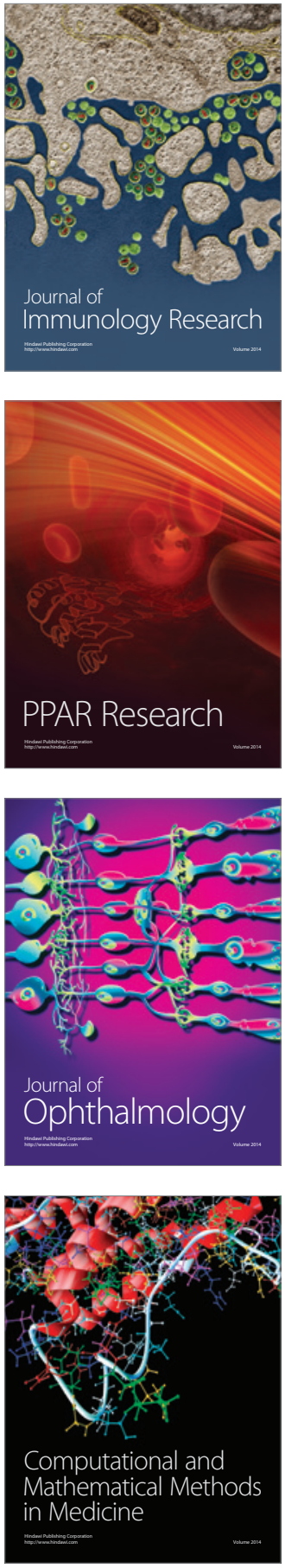

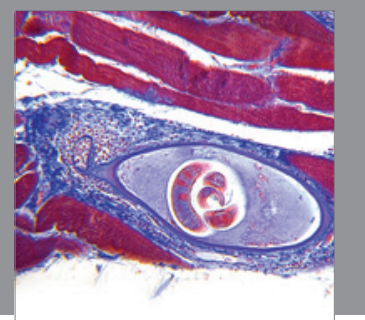

Gastroenterology

Research and Practice
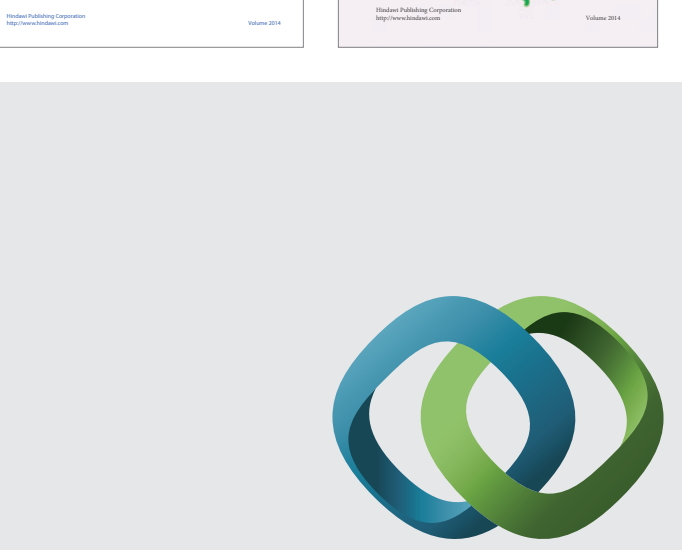

\section{Hindawi}

Submit your manuscripts at

http://www.hindawi.com
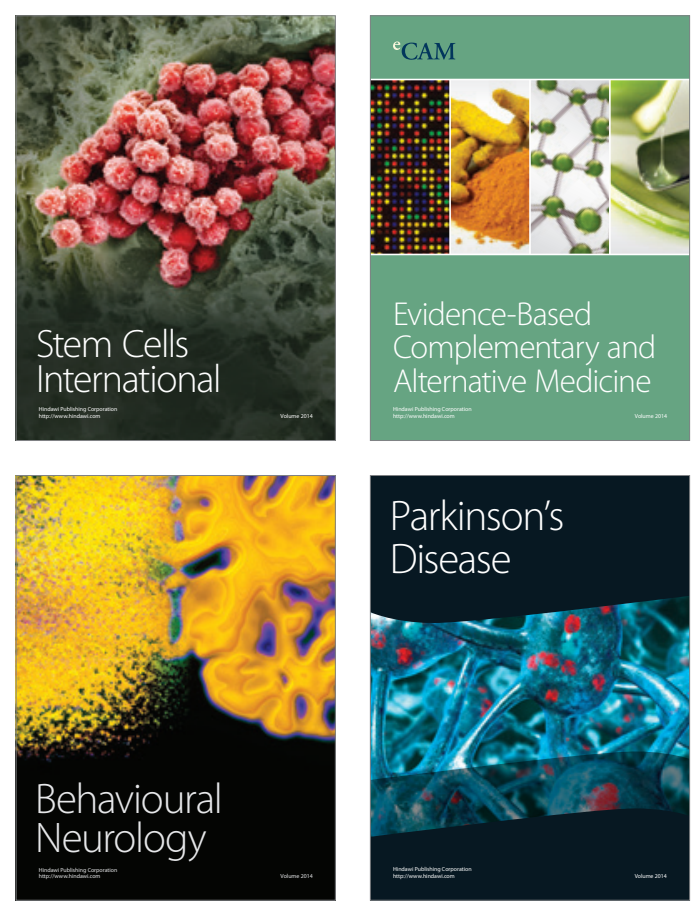

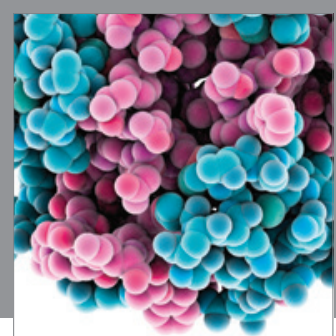

Journal of
Diabetes Research

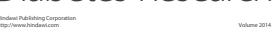

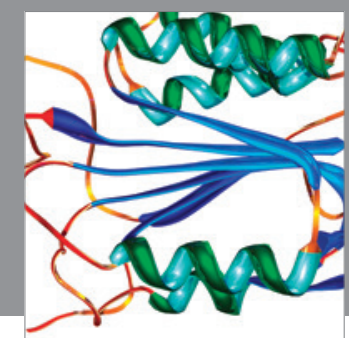

Disease Markers
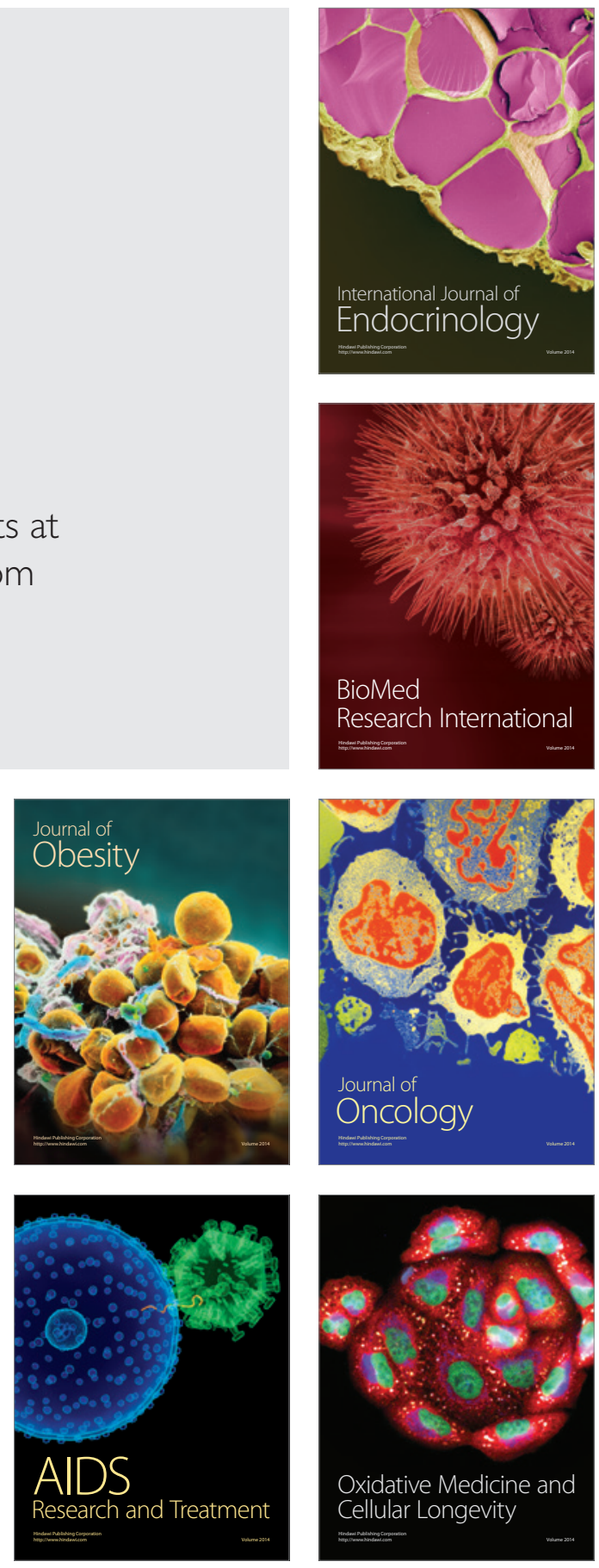